J. Lake Sci. (湖泊科学) , 2018, 30(6): 1655-1663

DOI 10. 18307/2018. 0617

(c) 2018 by Journal of Lake Sciences

\title{
鄱阳湖候鸟栖息地湖泊悬浮有机质的碳氮分布及来源分析一以大 湖池和沙湖为例
}

\author{
梁 越 $^{1}$, 肖化云 ${ }^{1 * *}$, 刘小真 ${ }^{2 * *}$, , 胡倩倩 ${ }^{1}$, 丁新航 ${ }^{1}$, 肖 浩 $^{1}$, 杨慧慧 $^{1}$ \\ ( 1 : 东华理工大学江西省大气污染成因与控制重点实验室,核资源与环境国家重点实验室培育基地, 水资源与环境工程 \\ 学院, 南昌 330013) \\ (2:南昌大学环境与化工学院, 鄱阳湖环境与资源利用教育部重点实验室,南昌 330047)
}

\begin{abstract}
摘 要: 以江西鄱阳湖国家级自然保护区的 2 个湖泊一一大湖池和沙湖为研究对象, 分析不同季节和水位悬浮有机质的 碳氮稳定同位素 $\left(\delta^{13} \mathrm{C}\right.$ 和 $\left.\delta^{15} \mathrm{~N}\right)$ 及碳氮比值 $(\mathrm{C} / \mathrm{N})$ 的变化特征, 甄别悬浮有机质的来源. 结果表明: 在不同水位条件下, 悬浮有机质的 $\delta^{13} \mathrm{C}$ 和 $\delta^{15} \mathrm{~N}$ 均存在差异显著性. 沙湖 5 月水位上涨时, 悬浮有机质 $\delta^{13} \mathrm{C}$ 最正, 均值为 $-26.4 \% 0 \pm 0.9 \%, 10$ 月退水后, $\delta^{13} \mathrm{C}$ 最负, 均值为 $-31.2 \% 01.1 \%$. 悬浮有机质 $\delta^{15} \mathrm{~N}$ 值在 5 月和 8 月较低 (范围为 $3.5 \% \sim 5.5 \%$ ), 10 月也相对 较低, 均值为 $6.1 \% \pm 0.6 \%$, 而 12 月相对较高 $(7.3 \% \sim 10.8 \%$ ). 悬浮有机质 $\mathrm{C} / \mathrm{N}$ 值在 10 月最低, 均值为 $6.5 \pm 0.6$, 小于 7 , 与其他各月的 $\mathrm{C} / \mathrm{N}$ 有显著差异, 而其他各月 $\mathrm{C} / \mathrm{N}$ 在 7.8 8.7 之间, 不存在显著差异. 大湖池悬浮有机质 $\delta^{13} \mathrm{C} 、 \delta^{15} \mathrm{~N}$ 各月 的变化趋势与沙湖类似, 并且两个湖泊在相同月份的 $\delta^{13} \mathrm{C} 、 \delta^{15} \mathrm{~N}$ 或 $\mathrm{C} / \mathrm{N}$ 均不存在显著差异, 但大湖池的 $\delta^{13} \mathrm{C}$ 和 $\delta^{15} \mathrm{~N}$ 比 沙湖的 $\delta^{13} \mathrm{C}$ 和 $\delta^{15} \mathrm{~N}$ 均值略偏正 $0.1 \% \sim 0.5 \%, \mathrm{C} / \mathrm{N}$ 比沙湖的 $\mathrm{C} / \mathrm{N}$ 略偏低 $0 \sim 0.4$. 有机 $\delta^{13} \mathrm{C} 、 \delta^{15} \mathrm{~N}$ 结合 $\mathrm{C} / \mathrm{N}$ 示踪表明, 大 湖池和沙湖的悬浮有机质在 5 月水位上涨和 8 月丰水期主要来源于河流运输的土壤有机质, 表层沉积物对 5 月悬浮有机 质也有一定贡献 ( $16 \%$ ), 水生浮叶植物对 8 月悬浮有机质有一定贡献 $(25 \%)$; 10 月秋季退水后悬浮有机质主要来源于藻 类 $(77 \%)$, 表层沉积物有一定贡献 $(23 \%) ; 12 、 3$ 和 4 月冬、春季枯水期悬浮有机质主要来源于表层沉积物, 候鸟粪便对 12 月悬浮有机质有较大贡献 ( $40 \%)$, 湿地植物碎屑对 3 和 4 月有较大贡献 ( $47 \%$ 和 $51 \%$ ).
\end{abstract}

关键词: 鄱阳湖;悬浮有机质; 同位素; 来源; 候鸟栖息地; 大湖池; 沙湖

\section{Source and distribution of carbon and nitrogen in the suspended organic matter in the mi- gratory bird habitat of Poyang Lake: The case study of Lake Dahuchi and Lake Shahu}

LIANG Yue ${ }^{1}$, XIAO Huayun ${ }^{1 * *}$, LIU Xiaozhen ${ }^{2 * *}$, HU Qianqian ${ }^{1}$, DING Xinhang ${ }^{1}$, XIAO Hao $^{1}$ \& YANG Huihui ${ }^{1}$

(1: Jiangxi Province Key Laboratory of the Causes and Control of Atmospheric Pollution, State Key Laboratory Breeding Base of Nuclear Resources and Environment, School of Water Resources \& Environmental Engineering, East China University of Technology, Nanchang 330013, P.R. China)

(2: Key Laboratory of Poyang Lake Environment and Resource Utilization, Ministry of Education, School of Resources Environmental \& Chemical Engineering, Nanchang University, Nanchang 330047, P.R. China)

Abstract: We discriminated the origins of suspended organic matters in different seasons and water levels by carbon and nitrogen stable isotopes $\left(\delta^{13} \mathrm{C}\right.$ and $\left.\delta^{15} \mathrm{~N}\right)$ and ratio $(\mathrm{C} / \mathrm{N})$ in Lake Dahuchi and Lake Shahu, national nature reserve of Poyang Lake in Jiangxi Province. The results showed that $\delta^{13} \mathrm{C}$ or $\delta^{15} \mathrm{~N}$ varied in different water levels. When water level rose in May, the $\delta^{13} \mathrm{C}$ reached the highest value with average $-26.4 \% \pm 0.9 \%$. In the dry season October, the $\delta^{13} \mathrm{C}$ has the lowest value, average

* 国家自然科学基金项目 (41563001)、国家重大研究与开发项目 (2016YTA0601000)、东华理工大学核资源与环境 国家重点实验室培育基地自主基金项目 (Z1610)、东华理工大学江西省大气污染成因与控制重点实验室开放基金 项目 (AE1602) 和东华理工大学博士科研启动金项目 (DHBK2015326) 联合资助. 2018-03-24 收稿; 2018-04-14 收修改稿. 梁越(1974 ), 女,博士;E-mail: liangyue@ ecit.cn.

** 通信作者; E-mail: xiaohuayun@ ecit.cn; liuxiaozhen@ ncu.edu.cn. 
$-31.2 \% \pm 1.1 \%$. The $\delta{ }^{15} \mathrm{~N}$ were of lower values in flooding seasons, however relativity high values in dry seasons. The $\mathrm{C} / \mathrm{N}$ in $\mathrm{Oc}-$ tober were lowest, average $6.5 \pm 0.6$ and less than 7. In other months $\mathrm{C} / \mathrm{N}$ were between 7.8 and 8.7 . The variation of $\delta^{13} \mathrm{C}, \delta^{15} \mathrm{~N}$ and $\mathrm{C} / \mathrm{N}$ ratio in each month was similar between Lake Dahuchi and Lake Shahu, without significant difference. However, the $\delta^{13} \mathrm{C}$ and $\delta^{15} \mathrm{~N}$ in Lake Dahuchi were more than $0.1 \% 0-0.5 \%$ and $\mathrm{C} / \mathrm{N}$ were lower than $0-0.4$ than those of Lake Shahu. At high water levels in May and August, the suspended organic matters were mainly from soil through rivers transportation, with $16 \%$ from surface sediment in May and 25\% from aquatic floating-leaved plant in August. The suspended organic matters in October were mainly from algae (77\%). At lower water levels of December, March and April, the suspended organic matters were mainly from surface sediments, and the excrement of migratory bird accounted for $40 \%$ in December. The phyto-detritus in wetland accounted for $47 \%$ and $51 \%$ in March and April, respectively.

Keywords: Poyang Lake; suspended organic matter; stable isotope; origin; migratory bird habitat; Lake Dahuchi; Lake Shahu

水环境中悬浮有机质的来源分为内源和外源, 水生植物、藻类和表层沉积物通常为内源; 土壤有机质、 陆地植物碎屑和废水有机质等为外源. 外部颗粒有机质常受环境因素的变化而呈现时空上的变化 ${ }^{[1-2]}$, 其输 人量与土地覆盖、植物呼吸、流域土壤利用 ${ }^{[3]}$ 、大气沉降和雨水径流 ${ }^{[4.5]}$ 密切相关,季节性活动如洪水和风暴 也显著地影响颗粒有机质的来源 ${ }^{[2]}$. 湖泊内源有机质如水生植物等受季节性光合作用和温度变化影响明 显. 水位的高度变化是湖泊悬浮有机质内外源又一重要的影响因素, 因其对湖泊水动力、化学和生态过程有 重要影响 ${ }^{[6]}$, 也会影响水的透明度、溶解氧浓度、营养盐浓度、悬浮物和沉积物的生物地球化学过程等 ${ }^{[7]}$. 鄱 阳湖是一过水性、吞吐型、季节性的浅水湖泊,全年水位变化很大, 因鄱阳湖流域在不同季节降雨量不同,水 面积在丰水期比枯水期往往大十几倍 ${ }^{[8]}$. 翻阳湖高度变化的水位导致了其边缘湖区复杂的水文过程 ${ }^{[9-10]}$, 丰水期与鄱阳湖及周边河流连通, 枯水期则独立成湖泊, 水位的高度变化深刻地影响着鄱阳湖边缘湖泊有 机质的来源.

碳氮稳定同位素结合碳氮比 $\left(\delta^{13} \mathrm{C} 、 \delta^{15} \mathrm{~N}\right.$ 和 $\left.\mathrm{C} / \mathrm{N}\right)$ 能有效地示踪地表水环境中悬浮有机质的来源、特性 及降解程度等生物地球化学问题 ${ }^{[11-13]}$, 因为有机质的内外源碳氮同位素特征值不同. 比如土壤有机质: $\delta^{13} \mathrm{C}$ 值为 $-25 \% \sim-22 \%, \delta^{15} \mathrm{~N}$ 值为 $0 \% 0 \sim 5 \%, \mathrm{C} / \mathrm{N}$ 为 $8 \sim 15$; 水生植物: $\delta^{13} \mathrm{C}$ 为 $-31 \% 0 \sim-26 \%, \delta^{15} \mathrm{~N}$ 为 $6 \% 0 \sim 11 \%$, $\mathrm{C} / \mathrm{N}$ 为 $10 \sim 15$; 陆地植物 $\mathrm{C} / \mathrm{N}$ 为 $15 \sim 30$; 藻类 $\delta^{13} \mathrm{C}$ 偏负, 为 $-42 \% \sim-24 \%$, 均值为 $-30 \%$, $\mathrm{C} / \mathrm{N}$ 通常小于 7 . 同时有机质的降解也将改变 $\mathrm{C} / \mathrm{N}^{[14]}$. 近些年来, 已有一些文献利用碳氮稳定同位素研究鄱阳湖的碳库组成 与循环、含氮物质的来源、水体污染途径及营养化程度、食物链结构组成和环境演化等方面 ${ }^{[15-18]}$, 对于鄱阳 湖区边缘的小湖泊研究则较少, 然而, 鄱阳湖主体航道通长江, 水体交换快, 营养盐易随主体航道流人长江, 鄱阳湖的碳氮循环和富营养化往往发生在其水流缓慢的边缘 ${ }^{[19-21]}$. 碳氮稳定同位素示踪能较好地反映边缘 湖区营养物质的来源,有利于鄱阳湖区的环境保护.

鄱阳湖候鸟保护区主要位于鄱阳湖边缘湖区,每年的 10 月底至次年 3 月初的枯水季节,其独特的季节 性湖泊及湖滩草地是候鸟越冬栖息的优良环境, 人类经济活动也较少,候鸟栖息于湖边、泥滩或深浅水区域 中. 候鸟在冬春季栖息对于湖泊营养物质的影响研究很少见报道. 本研究选择鄱阳湖区的 2 个边缘湖 泊一一大湖池和沙湖作为主要研究对象, 这两个湖泊也属于鄱阳湖候鸟保护区范围, 是候鸟栖息地. 在对湖 泊采样的同时也对其邻近水域——赣江北支和修河进行采样, 分析悬浮有机质的碳氮稳定同位素的特征 值,探讨不同月份和水位条件下悬浮有机质的来源.

\section{1 材料与方法}

\section{1 研究区域与样品采集}

大湖池和沙湖位于江西省北部, 永修县境内, 吴城镇的西面, 是鄱阳湖两大支流赣江北支和修河尾问复 合三角洲上的堤间洼地 (图 1), 出、人湖水流随江、河水位而变, 流向不定. 在每年鄱阳湖退水后的枯水季 节, 成为湖滩地的滞水性湖泊, 在洪水季节与周边河流和鄱阳湖主体连成一片. 湖中苔草茂盛, 鱼虾资源丰 富, 是越冬候鸟受食和栖息的良好场所, 是鄱阳湖候鸟主要保护区范围 ${ }^{[22]}$.

大湖池和沙湖的水深随季节变化而变化, 本研究根据季节和水位变化在 2016 年 12 月中旬至 2017 年 10 月初进行采样, 分别选择 12 月冬季枯水期 (候鸟正栖息)、3 月春季枯水期 (候鸟已离开 ${ }^{[23]}$ )、4 月春季枯 
水期、 5 月水位上涨期、 8 月丰水期及 10 月秋季枯水期 (湖水退去 1 个月). 8 月丰水期水深 $6 \mathrm{~m}$ 左右, 10 月 至次年的 4 月枯水期水深 $0.3 \sim 1.0 \mathrm{~m}$ 左右, 5 月水位上涨时期水深 $2.5 \sim 3.5 \mathrm{~m}, 5-8$ 月为汛期. 水样采集使用 有机玻璃采水器,枯水期由于水浅,在水面 $0.1 \mathrm{~m}$ 以下采集,丰水期在水面 $0.5 \mathrm{~m}$ 处采集. 采样点见图 1 , GPS 定位, 因为水位差异, 涨水期和丰水期乘船采样, 枯水期穿水裤下水采样, 每次采样点差别不大. 同时乘船采 集了与湖泊相邻的赣江和修河的水样. 每次各湖泊和河流分别采集 10 个左右水样,储存于干净的聚乙烯瓶 内. 叶绿素荧光仪测定叶绿素a (Chl.a) 浓度.

在采集水样的同时在相同点采集了表层沉积物, 12 月还采集了候鸟粪便和湿地植物各 5 个,这些固态 物质冷冻干燥并研磨过笁后供碳氮同位素测定. 其他如土壤、水生植物的碳氮同位素值见表 1 中的参考 文献.

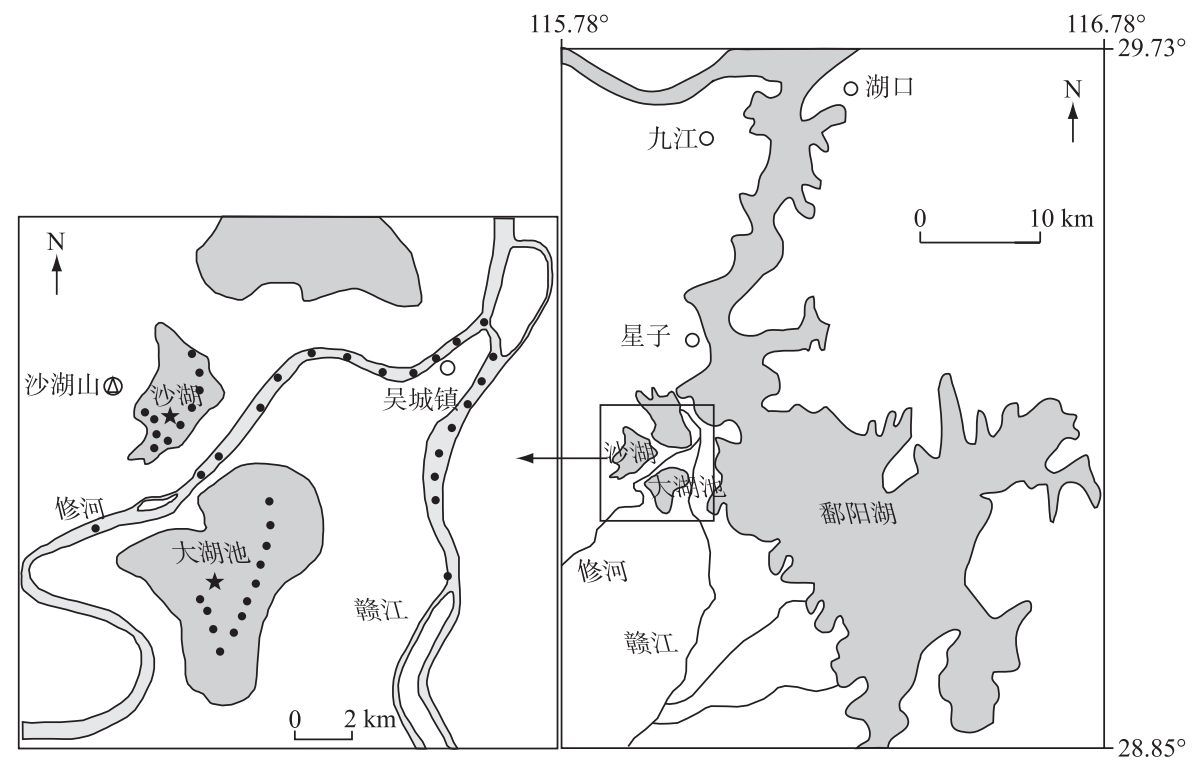

图 1 沙湖和大湖池及周边水域采样点

Fig.1 Sampling sites in Lake Shahu and Lake Dahuchi and around their watersheds

\section{2 悬浮有机质碳氮同位素前处理和测定}

悬浮有机质碳氮同位素预处理: 水样 $3 \mathrm{~L}$ 分 2 次进行过滤 $(0.7 \mu \mathrm{m}$ 的 Whaterman $\mathrm{GF} / \mathrm{F}$ 滤膜,预先在 $450^{\circ} \mathrm{C}$ 马弗炉灼烧 $4 \mathrm{~h}$ 以上), 留在滤膜上的悬浮物保存于离心管中, 分别用于碳氮同位素分析. 用于碳同位 素分析的悬浮物用 $1 \mathrm{~mol} / \mathrm{L}$ 的盐酸溶液酸洗, 静置过夜, 次日离心, 超纯水清洗, 直至上清液接近中性, 冷冻 干燥后用于总有机碳 (TOC) 含量和碳同位素分析. 用于氮同位素分析的悬浮物直接冷冻干燥后供总氮含量 及氮同位素分析.

有机碳氮的含量及其同位素的测定是利用元素分析仪和同位素质谱仪 (MAT253) 联用. $\delta^{15} \mathrm{~N}$ 以大气 $\mathrm{N}_{2}$ 和 IAEA 硝酸钾为参比气和国际标准, 分析误差为 $\pm 0.2 \%$. $\delta^{13} \mathrm{C}$ 以美国南卡罗莱纳州白严系 Pee Dee 组拟箭 石化石作为标准品, 分析误差为 $\pm 0.2 \%$.

$\delta^{15} \mathrm{~N}\left(\right.$ 或 $\left.\delta^{13} \mathrm{C}\right)=\left(R_{\text {样品 }} / R_{\text {标准 }}-1\right) 1000 \%\left(\mathrm{R}={ }^{15} \mathrm{~N} /{ }^{14} \mathrm{~N}\left(\right.\right.$ 或 $\left.{ }^{13} \mathrm{C} /{ }^{12} \mathrm{C}\right)$ 自然丰度比).

\section{3 悬浮有机质来源的贡献率估算}

利用同位素混合模型 $\left(\delta=\delta_{a} * f_{a}+\delta_{b} * f_{b}+\delta_{c} * f_{c}, f_{a}+f_{b}+f_{c}=1, a, b, c\right.$ 为端元, $f$ 为贡献比例 $)$ 估算各月 有机质来源的贡献比例 ${ }^{[24]}$.

\section{4 统计与作图}

运用 SPSS 19.0 软件进行相关性及 One ANOVA-Tukey 差异显著性分析, Sigmaplot 11.0 软件作图. 


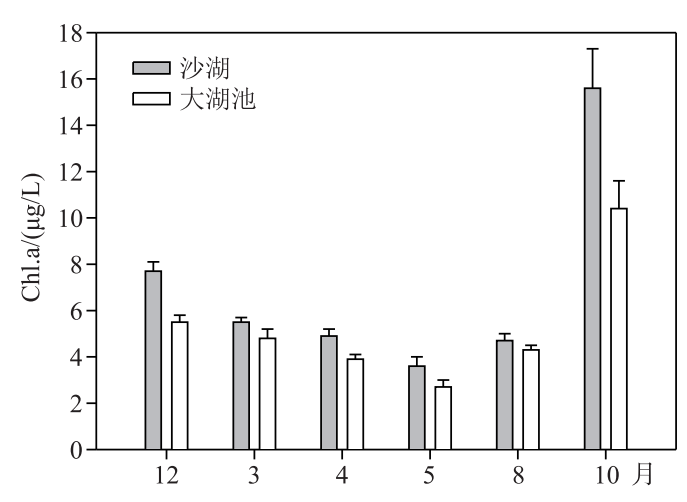

图 2 沙湖和大湖池在不同月份 Chl.a 浓度

Fig. 2 Chl.a concentrations in different months in Lake Shahu and Lake Dahuchi

\section{2 结果与讨论}

\section{1 叶绿素 a 浓度}

Chl.a 反映藻类的含量, 大湖池和沙湖 Chl.a 浓度 在 10 月显著比其他月份高, 分别为 $10.4 \pm 1.2$ 和 $15.6 \pm$ $1.7 \mu \mathrm{g} / \mathrm{L}$ (图 2), TN/TP(摩尔比) 分别为 $9.2: 1$ 和 7.4: $1^{[25]}$, 低于 $16: 1$, 适合藻类生成, 10 月初是秋季, 水位 低, 光照和温度 $\left(25 \sim 30^{\circ} \mathrm{C}\right)$ 也有利于藻类形成, 湖面 可见藻类聚集, 沙湖更明显. 12 月大湖池和沙湖 Chl.a 浓度分别为 $6.5 \pm 0.3$ 和 $7.7 \pm 0.4 \mu \mathrm{g} / \mathrm{L}, \mathrm{TN} / \mathrm{TP}$ 高于 16 : 1 , 冬季寒冷, 光照和温度较低, 不适合藻类大量形成. 5 月和 8 月湖水混浊, 水体透明度差, 不适合藻类光合 作用, Chl.a 浓度最低, 低于 $4 \mu \mathrm{g} / \mathrm{L}$. 其他月份, Chl. a 浓度介于 $4 \sim 6 \mu \mathrm{g} / \mathrm{L}$ 之间, TN/TP 高于 $16: 1^{[25]}$, 未 藻类大量聚集.

\section{2 悬浮有机质碳氮同位素在不同水位的变化特征}

湖泊悬浮有机质在不同水位时期的 $\delta^{13} \mathrm{C}$ 值有显著性差异, 也就是说枯水期、丰水期和水位退落后的 $\delta^{13} \mathrm{C}$ 值存在显著差异 (如箱形图上标注的 $\mathrm{a}, \mathrm{b}, \mathrm{c}$ 字母, $P<0.05$ ) (图 3). 例如, 虽然沙湖在 $12 、 3$ 和 4 月枯水期的 悬浮有机质 $\delta^{13} \mathrm{C}$ 差别不大, 不存在差异显著性, 范围为 $-27.1 \% 0 \sim-30.8 \% 0$ (图 3) ; 水位上涨后的 5 月和丰水 期的 8 月悬浮有机质的 $\delta^{13} \mathrm{C}$ 不存在显著差异, 但是与枯水期有显著性差异,均值明显比枯水期偏正了 $2 \%$, 分别为 $-26.1 \% 0$ 和 $-26.4 \% 0 ; 10$ 月秋季枯水期, 湖水刚退去 1 个月左右, $\delta^{13} \mathrm{C}$ 范围为 $-29.9 \% 0 \sim-32.3 \%$, 均值为 $-31.2 \% 0 \pm 1.0 \%$, 与各个月相比有显著性差异, $\delta^{13} \mathrm{C}$ 值偏负了 $3 \% 0 \sim 5 \%$.

沙湖的悬浮有机质 $\delta^{15} \mathrm{~N}$ 在 12 月与其他月份相比存在显著差异 (图 3), 比其他各月 $\delta^{15} \mathrm{~N}$ 明显高, 均值 为 $8.0 \% 0 \pm 1.2 \%$; 涨水后的 5 月和 8 月 $\delta^{15} \mathrm{~N}$ 最低, 均值分别为 $4.4 \%$ 和 $4.8 \%$, 与枯水期的各月 $\delta^{15} \mathrm{~N}$ 都有显著 差异, 其他月份 $\delta^{15} \mathrm{~N}$ 在 $6.0 \% 0 \sim 6.6 \%$ 之间, 没有显著差异.

沙湖的 $\mathrm{C} / \mathrm{N}$ 在 10 月最低, 均值为 $6.5 \pm 0.6$, 小于 7 , 与其他各月相比有显著差异 (图 3 ); 其他各月的 $\mathrm{C} / \mathrm{N}$ 均值大于 7.8 ,其间不存在显著差异.

大湖池和沙湖的悬浮有机质 $\delta^{13} \mathrm{C} 、 \delta^{15} \mathrm{~N}$ 或 $\mathrm{C} / \mathrm{N}$ 在不同水位时期的变化趋势类似 (图 3, 图 4), 而且 2 个 湖泊之间在相同月份的 $\delta^{13} \mathrm{C} 、 \delta^{15} \mathrm{~N}$ 或 $\mathrm{C} / \mathrm{N}$ 均不存在显著差异 $(P>0.05)$, 但是大湖池的 $\delta^{13} \mathrm{C}$ 和 $\delta^{15} \mathrm{~N}$ 比沙湖 的 $\delta^{13} \mathrm{C}$ 和 $\delta^{15} \mathrm{~N}$ 略偏正, C/ $\mathrm{N}$ 比沙湖的 $\mathrm{C} / \mathrm{N}$ 略偏低, 例如: 大湖池各月 $\delta^{13} \mathrm{C}$ 均值分别为 $-28.8 \%$ 、 $-28.4 \%$, $-27.9 \% 0 、-26.0 \% 0 、-26.4 \% 0$ 和 $-30.7 \% 0$, 略偏正于沙湖相同月份的 $\delta^{13} \mathrm{C}$ 均值 $-29.0 \% 0 、-28.5 \%$ 、 $-28.1 \% 0$ 、 $-26.1 \% 0 、-26.5 \% 0$ 和 $-31.2 \% 0$; 大湖池的 $\delta^{15} \mathrm{~N}$ 各月均值分别为 $8.5 \%$ 、6.5\% 、6.2\% 、5.0\% 、 $5.4 \% 0$ 和 $6.2 \% 0$, 略偏 正于沙湖相同月份的 $\delta^{15} \mathrm{~N}$ 均值 $8.0 \% 0 、 6.2 \% 0 、 6.0 \% 0 、 4.4 \% 0 、 4.8 \% 0$ 和 $6.1 \% 0$; 大湖池的 $\mathrm{C} / \mathrm{N}$ 各月均值分别为 $8.4 、 8.3 、 8.0 、 8.9 、 8.6$ 和 6.8 , 略偏低于沙湖相同月份的 $\mathrm{C} / \mathrm{N}$ 均值 $8.8 、 8.6 、 7.8 、 9.2 、 8.8$ 和 6.5. 也就是说, 2 个 湖泊的悬浮有机质碳氮同位素在时间上变化一致, 在空间上差异也不大, 这是由于 2 个湖泊地理位置较接 近, 周边有相似的地理环境, 表明它们悬浮有机质的来源较一致.

\section{3 湖泊周边环境中有机质的碳氮同位素特征}

有机 $\delta^{13} \mathrm{C} 、 \delta^{15} \mathrm{~N}$ 结合 $\mathrm{C} / \mathrm{N}$ 可以有效地示踪水环境中有机质的来源 ${ }^{[26-28]}$, 因为不同来源的有机质的碳氮 同位素有各自的相对范围 ${ }^{[29-31]}$. 湖泊内源和外源有机质的 $\delta^{13} \mathrm{C} 、 \delta^{15} \mathrm{~N}$ 与 $\mathrm{C} / \mathrm{N}$ 明显不同 (表 1), 例如湖泊内源 的表层沉积物的 $\delta^{13} \mathrm{C}$ 为 $-27.4 \% 0 \pm 1.7 \%$ (表 1), 比外源土壤有机质 $\delta^{13} \mathrm{C}(-25.4 \% 0 \pm 0.6 \% 0)$ 偏负; $\delta^{15} \mathrm{~N}$ 为 $6.5 \% 0 \pm 1.3 \%$, 比土壤有机质 $\delta^{15} \mathrm{~N}(3.8 \% 0 \pm 0.4 \% 0)$ 偏正; $\mathrm{C} / \mathrm{N}$ 为 $7.9 \pm 0.9$, 比土壤有机质 $\mathrm{C} / \mathrm{N}(12.6 \pm 0.7)$ 偏低. 又如河流中悬浮有机质的碳氮同位素值在枯水期、水位上涨和丰水期也明显不同, 5 月涨水季节, 赣江北支 和修河的悬浮有机质 $\delta^{13} \mathrm{C}$ 和 $\mathrm{C} / \mathrm{N}$ 较高: $\delta^{13} \mathrm{C}$ 分别为 $27.1 \%{ }^{\circ} \pm 1.3 \%$ 和 $-26.4 \% \pm 1.4 \%, \mathrm{C} / \mathrm{N}$ 分别为 $12.7 \pm 2.1$ 和 $10.9 \pm 1.7, \delta^{15} \mathrm{~N}$ 相对较低, 为 $4.8 \% 0 \pm 01.2 \% 0$ 和 $4.6 \% 0 \pm 0.7 \%$, 两河流的悬浮有机质的碳氮同位素值介于土壤 

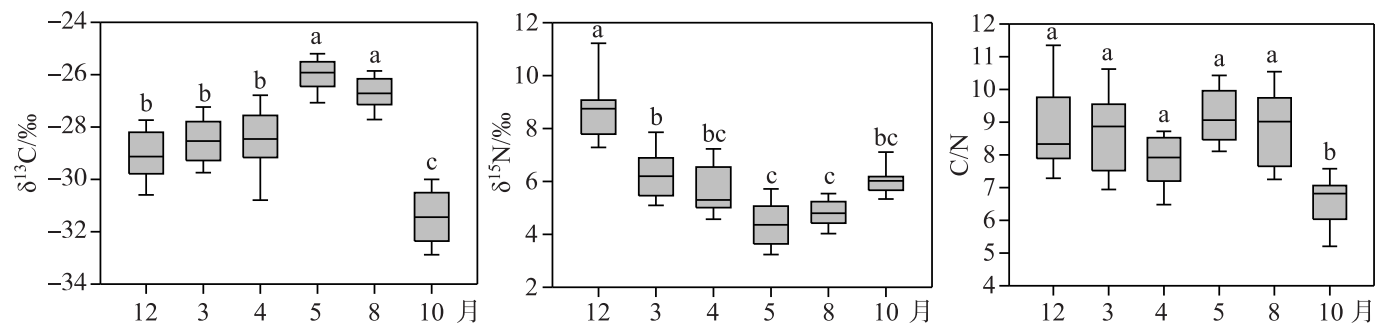

图 3 沙湖悬浮有机质 $\delta^{13} \mathrm{C} 、 \delta^{15} \mathrm{~N}$ 和 $\mathrm{C} / \mathrm{N}$ 在各月的变化特征

Fig. 3 Variation of $\delta^{13} \mathrm{C}, \delta^{15} \mathrm{~N}$ and $\mathrm{C} / \mathrm{N}$ of suspended organic matter in different months in Lake Shahu
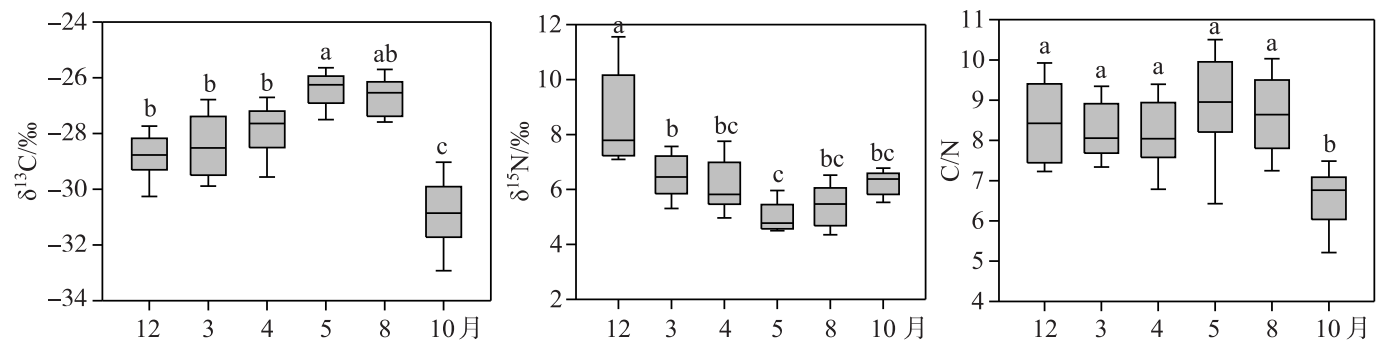

图 4 大湖池悬浮有机质 $\delta^{13} \mathrm{C} 、 \delta^{15} \mathrm{~N}$ 和 $\mathrm{C} / \mathrm{N}$ 在各月的变化特征

Fig.4 Variation of $\delta^{13} \mathrm{C}, \delta^{15} \mathrm{~N}$ and $\mathrm{C} / \mathrm{N}$ of suspended organic matter in different months in Lake Dahuchi

有机质和陆地植物的碳氮同位素值之间 ( 表 1), 是土壤有机质和陆地植物碎屑的混合. 8 月丰水期,河流悬浮有机质的 $\delta^{15} \mathrm{~N}$ 比 5 月高 $2 \%$, 表明大雨冲刷下含更高 $\delta^{15} \mathrm{~N}$ 的有机质进 人河流. 这些明显差异的碳氮同位素特征值能 够较好地区分湖泊有机质在不同水位期的内 源和外源.

\section{4 河流与湖泊在不同水位的连通情况}

处于河流三角洲冲击平原的鄱阳湖边缘 湖泊与河流的连通或分离是由水位的高低所 决定. 鄱阳湖流域从 5 月汛期到 8 月处于雨水 季节,水位上涨, 河水可能进人湖泊; 从 9 月初 到次年 4 月处于枯水季节, 水位下降, 河水与 湖水分离. 悬浮有机质碳氮同位素的变化可以 反映河湖之间的连通或分离. 5 月水位上涨, 河 流的 $\delta^{13} \mathrm{C} 、 \delta^{15} \mathrm{~N}$ 与湖泊的 $\delta^{13} \mathrm{C}(-26.4 \% \pm$ $0.9 \% 0)$ 和 $\delta^{15} \mathrm{~N}(4.4 \% 0 \pm 0.5 \% 0)$ 差别不大 (表 1 , 图 3, 图 4), 是涨水时河水输人湖泊的结果, 此 时河湖连通; 8 月丰水期,湖泊的 $\delta^{13} \mathrm{C}$ 与河流 的 $\delta^{13} \mathrm{C}$ 差别不大, 但是 $\delta^{15} \mathrm{~N}(4.8 \% 0 \pm 1.2 \% 0)$ 和 $\mathrm{C} / \mathrm{N}(8.4 \% 0 \pm 1.4 \% 0)$ 比河流的 $\delta^{15} \mathrm{~N}(6.5 \% \pm \pm$
表 1 湖泊周边环境有机质的 $\delta^{13} \mathrm{C} 、 \delta^{15} \mathrm{~N}$ 与 $\mathrm{C} / \mathrm{N}$ 特征值

Tab. 1 The characteristics of $\delta^{13} \mathrm{C}, \delta^{15} \mathrm{~N}$ and $\mathrm{C} / \mathrm{N}$ of organic matters around lakes

\begin{tabular}{|c|c|c|c|c|}
\hline 采样点 & 类型 & $\delta^{13} \mathrm{C} / \% 0$ & $\delta^{15} \mathrm{~N} / \% 0$ & $\mathrm{C} / \mathrm{N}$ \\
\hline 修河 4 月 & 悬浮物 & $-28.1 \pm 1.0$ & $5.2 \pm 1.1$ & $7.8 \pm 1.2$ \\
\hline 赣江北支 4 月 & 悬浮物 & $-27.5 \pm 0.7$ & $6.6 \pm 1.4$ & $7.3 \pm 1.5$ \\
\hline 修河 5 月 & 悬浮物 & $-27.1 \pm 1.3$ & $4.6 \pm 0.7$ & $12.7 \pm 2.1$ \\
\hline 赣江北支 5 月 & 悬浮物 & $-26.4 \pm 1.4$ & $4.8 \pm 1.2$ & $10.9 \pm 1.7$ \\
\hline 修河 8 月 & 悬浮物 & $-27.3 \pm 1.1$ & $6.5 \pm 1.0$ & $9.6 \pm 1.2$ \\
\hline 赣江北支 8 月 & 悬浮物 & $-26.6 \pm 0.9$ & $6.9 \pm 1.2$ & $9.1 \pm 1.8$ \\
\hline 赣江沿岸 ${ }^{1}$ & 土壤 & $-25.0 \pm 0.5$ & $3.2 \pm 0.4$ & $17.4 \pm 0.8$ \\
\hline 修河沿岸 ${ }^{1}$ & 土壤 & $-25.4 \pm 0.6$ & $3.8 \pm 0.4$ & $12.6 \pm 0.7$ \\
\hline 赣江北支沿岸 ${ }^{1}$ & 陆地植物 & $-28.7 \pm 0.6$ & $7.4 \pm 3.0$ & $26.6 \pm 7.9$ \\
\hline 修河沿岸 ${ }^{1}$ & 陆地植物 & $-29.3 \pm 0.2$ & $9.4 \pm 0.9$ & $20.7 \pm 0.2$ \\
\hline 大湖池 & 湿地植物 & $-27.9 \pm 0.5$ & $6.9 \pm 0.2$ & $10.3 \pm 0.7$ \\
\hline 沙湖 & 湿地植物 & $-28.4 \pm 0.4$ & $7.4 \pm 0.2$ & $12.9 \pm 0.9$ \\
\hline 沙湖荇菜 (2) & 浮叶植物 & $-27.0 \pm 0.4$ & $8.0 \pm 0.9$ & / \\
\hline 沙湖马来眼子菜 ${ }^{2}$ & 沉水植物 & $-23.5 \pm 0.4$ & $8.3 \pm 0.4$ & / \\
\hline 沙湖 & 各月表层沉积 & $-27.4 \pm 1.7$ & $6.5 \pm 1.3$ & $7.9 \pm 0.9$ \\
\hline 沙湖 & 候鸟粪便 & $-29.3 \pm 0.5$ & $8.9 \pm 0.7$ & $10.4 \pm 0.8$ \\
\hline
\end{tabular}

(1)参考文献[20]; (2)参考文献[33].

$1.0 \% 0$ ) 和 $\mathrm{C} / \mathrm{N}(9.6 \pm 1.2)$ 低(表 1), 表明河水和湖水在丰水期虽然连通, 但鄱阳湖受长江汛期高水位顶托的 作用, 水流缓慢 ${ }^{[32]}$, 湖泊与河流水交换不彻底. 4 月枯水期, 河流与湖泊有机质的 $\delta^{13} \mathrm{C} 、 \delta^{15} \mathrm{~N}$ 和 $\mathrm{C} / \mathrm{N}$ 有显著 
差异,湖水和河水分离,湖泊有机质碳氮同位素值的变化是自身生物地球化学作用的结果.

\section{5 悬浮有机质的来源}

悬浮有机质在不同月份和水位的来源有较大差别. 沙湖 10 月份悬浮有机质明显地落在藻类的 $\delta^{13} \mathrm{C}$ 、 $\delta^{13} \mathrm{~N}$ 与 $\mathrm{C} / \mathrm{N}$ 的关系范围内 (图 5), 叶绿素 $\mathrm{a}$ 浓度在 10 月最高, 为 $15.6 \pm 1.7 \mu \mathrm{g} / \mathrm{L}$ (图 2), Chl. a 浓度与 $\delta^{13} \mathrm{C}$ 的 相关性分析表明它们之间具有显著相关性 $(r=-0.713, P<0.05)$, 表明藻类是悬浮有机质的主要贡献者; 另 外, 10 月的悬浮有机质 $\delta^{13} \mathrm{C} 、 \delta^{13} \mathrm{~N}$ 与 $\mathrm{C} / \mathrm{N}$ 也落在表层沉积物的 $\delta^{13} \mathrm{C} 、 \delta^{13} \mathrm{~N}$ 与 $\mathrm{C} / \mathrm{N}$ 一定范围 (图 5), 10 月枯 水期, 水深 $1 \mathrm{~m}$ 以下, 受风浪作用会引起表层沉积再悬浮. $3 、 4$ 和 12 月悬浮有机质落在表层沉积物的 $\delta^{13} \mathrm{C}$ 、 $\delta^{15} \mathrm{~N}$ 与 $\mathrm{C} / \mathrm{N}$ 的关系范围内 (图 5b, 表 1), 12 月的悬浮有机质也与候鸟粪便密切相关 (图 5), 3 和 4 月悬浮有 机质也与湿地植物碎屑的 $\delta^{13} \mathrm{C}$ 和 $\delta^{15} \mathrm{~N}$ 有关, 春季经常雨水冲刷湿地植物碎屑流入湖内, 表明 $3 、 4$ 和 12 月表 层沉积物是悬浮有机质的主要贡献者, 冬、春季枯水期水浅, 风浪的作用使表层沉积物发生再悬浮 ${ }^{[33]}$, 候鸟 每年的 10 月底至次年的 3 月初会栖息在湖泊,受食水域的水深一般在 $20 \mathrm{~cm}$ 左右,受食时间很长 $(10 \mathrm{~h}$ 左 右), 挖泥的深度 $10 \sim 20 \mathrm{~cm}$, 以湿地植物的嫩芽或根茎为食, 夜宿于水深 $30 \mathrm{~cm}$ 左右的浅水水域 ${ }^{[34]}$, 也易引 起表层沉积再悬浮. 3 月和 4 月的 $\delta^{13} \mathrm{C} 、 \delta^{15} \mathrm{~N}$ 和 $\mathrm{C} / \mathrm{N}$ 与 12 月的 $\delta^{13} \mathrm{C} 、 \delta^{15} \mathrm{~N}$ 和 $\mathrm{C} / \mathrm{N}$ 有较大区别, 是由于春季气 温逐渐升高, 又经常小雨, 湿地土壤有机质径流携带一定的湿地植物碎屑进人湖内, 而且有机质的降解作用 也较强, 尤其是候鸟春季 3 月初离开栖息地后, 粪便也容易降解, 这些混合作用容易改变 $\delta^{13} \mathrm{C} 、 \delta^{15} \mathrm{~N}$ 和 $\mathrm{C} / \mathrm{N}$ 的组成. 5 月和 8 月的悬浮有机质的 $\delta^{13} \mathrm{C} 、 \delta^{15} \mathrm{~N}$ 和 $\mathrm{C} / \mathrm{N}$ 与河流悬浮有机质 $\delta^{13} \mathrm{C} 、 \delta^{15} \mathrm{~N}$ 与 $\mathrm{C} / \mathrm{N}$ 密切相关 (图 $5)$, 都主要落在土壤有机质的 $\delta^{13} \mathrm{C} 、 \delta^{15} \mathrm{~N}$ 和 $\mathrm{C} / \mathrm{N}$ 的关系范围内, 表明土壤有机质是 5 月和 8 月的河流和湖泊 悬浮有机质的主要贡献者, 5 月表层沉积对悬浮物也有一定贡献(图 5), 5 月水位上涨, 来自于河流的土壤有 机质等进入湖泊, 水深 $2 \sim 3 \mathrm{~m}$, 风浪的作用也可能使表层沉积悬浮, 8 月丰水期, 水深 $6 \mathrm{~m}$ 左右, 风浪的作用 已较少能引起表层沉积悬浮. 水生植物荇菜的 $\delta^{13} \mathrm{C}$ 和 $\mathrm{C} / \mathrm{N}$ 也较接近于 8 月的悬浮有机质范围 (图 $5 \mathrm{a}$ ), 表明 水生浮叶植物荇菜 ${ }^{[34]}$ 在春夏季生长旺盛时对悬浮有机质有一定贡献. 陆地植物、湿地植物及沉水植物马来 眼子菜 ${ }^{[34]}$ (较少) 的 $\delta^{13} \mathrm{C} 、 \delta^{15} \mathrm{~N}$ 和 $\mathrm{C} / \mathrm{N}$ 与各月的悬浮颗粒物 $\delta^{13} \mathrm{C} 、 \delta^{15} \mathrm{~N}$ 和 $\mathrm{C} / \mathrm{N}$ 的关系都较疏远 (图 5), 表明 它们对悬浮颗粒物的贡献较弱.

利用同位素混合模型估算各月有机质来源的贡献比例, 取 $\mathrm{C}$ 或 $\mathrm{N}$ 稳定同位素值计算. 因为鄱阳湖的边 缘湖泊如沙湖和大湖池在枯水期的 10 月至次年的 4 月几乎处于封闭状态, 很少与外界进行水交换, 所以有 机质的来源根据各月的情况分别取两个端元进行贡献比例计算. 10 月两个端元藻类 $\left(\delta^{13} \mathrm{C}\right.$ 和 $\delta^{15} \mathrm{~N}$ 值为 $-32 \% 0$ 和 6.2\% ) 和表层沉积物的贡献比例分别为 $77 \%$ 和 $23 \% ; 12$ 月候鸟粪便和表层沉积物两个端元贡献比 例分别约为 $40 \%$ 和 $60 \% ; 3$ 月湿地植物和表层沉积物两个端元贡献比例分别约为 $47 \%$ 和 $53 \% ; 4$ 月湿地植物 和表层沉积物两个端元贡献比例分别约为 $51 \%$ 和 $49 \%$; 5 月水位上涨, 两河流悬浮物 (运输的土壤有机质) 和湖泊周边土壤有机质取平均值作为一个混合土壤有机质端元, 表层沉积物作为另一个端元, 则两者的贡 献比例分别约为 $84 \%$ 和 $16 \%$; 8 月丰水期, 混合土壤有机质和水生植物荇菜两个端元贡献的比例分别约为 $75 \%$ 和 $25 \%$.

大湖池各月悬浮有机质来源与沙湖相似, 是由它们相似的地理位置和周边环境所决定.

\section{6 鄱阳湖候鸟栖息地湖泊与鄱阳湖主体悬浮有机质碳氮同位素变化特征及来源比较}

湖泊有机质的碳氮同位素变化特征也与湖泊的营养状态相关,贫中营养湖泊有机质的 $\delta^{13} \mathrm{C}$ 和 $\delta^{15} \mathrm{~N}$ 变 化幅度小, 而富营养化湖泊 $\delta^{13} \mathrm{C}$ 和 $\delta^{15} \mathrm{~N}$ 变化幅度大 ${ }^{[35-36]}$, 鄱阳湖主体航道长, 通长江, 处于中营养化 ${ }^{[37]}$, 有 机质的 $\delta^{13} \mathrm{C}$ 和 $\delta^{15} \mathrm{~N}$ 的变化幅度较小 (低于 $2 \%$ ), 主要是湖泊内源如藻类和水生植物光合作用和氮转化的 季节变化所引起 ${ }^{[17]}$. 而候鸟栖息地湖泊位于鄱阳湖边缘, 湖盆小, 丰水期处于中营养化, 枯水期处于富营养 化 ${ }^{[25,38]}$, 有机质 $\delta^{13} \mathrm{C}$ 和 $\delta^{15} \mathrm{~N}$ 的变化幅度大 $(2 \% 0 \sim 5 \%$ ), 是因为丰水期湖泊与河流连通进行水交换, 有机质 主要来自于外源如土壤有机质, 枯水期与河流断开, 有机质主要来源于内源湿地植物和沉积物, 而内源与外 源有机质 $\delta^{13} \mathrm{C}$ 或 $\delta^{15} \mathrm{~N}$ 差异较大.

在不同水位和季节鄱阳湖主体与候鸟栖息地边缘湖泊悬浮有机质 $\delta^{13} \mathrm{C}$ 或 $\delta^{15} \mathrm{~N}$ 的变化也不同,鄱阳湖 主体丰水期 $\delta^{13} \mathrm{C}$ 偏负, 枯水期偏正, 与栖息地边缘湖泊的悬浮有机质 $\delta^{13} \mathrm{C}$ 变化相反, 这是因为鄱阳湖主体 有机质的贡献是 C3 植物, 是不同季节碳同位素分馏所致 ${ }^{[17]}$, 而栖息地边缘湖泊是河流冲击平原, 丰水期土 

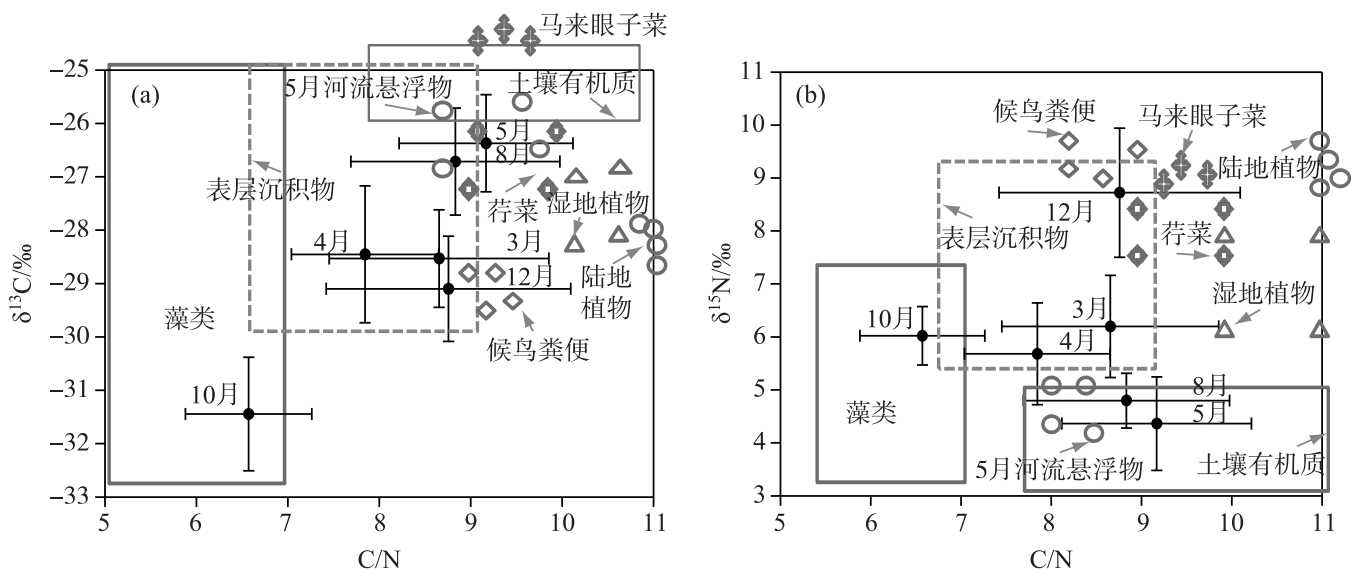

图 5 沙湖各月悬浮有机质及其潜在来源的有机质 $\delta^{13} \mathrm{C}(\mathrm{a}) 、 \delta^{15} \mathrm{~N}(\mathrm{~b})$ 与 $\mathrm{C} / \mathrm{N}$ 关系图

Fig.5 Potential sources of suspended organic matter analyzed by $\delta^{13} \mathrm{C}(\mathrm{a}), \delta^{15} \mathrm{~N}$ (b) versus $\mathrm{C} / \mathrm{N}$ in different months in Lake Shahu

壤有机质贡献最大, $\delta^{13} \mathrm{C}$ 偏正, 枯水期是湖内湿地植物和表层沉积物所贡献, $\delta^{13} \mathrm{C}$ 偏负. 翻阳湖主体悬浮有 机质 $\delta^{15} \mathrm{~N}$ 在不同季节和水位总体上变化较小,虽然部分有机氮的来源有生活污物、化肥,但大都来源于土壤 有机质 ${ }^{[17]}$. 而栖息地边缘湖泊有机氮在冬季枯水期有表层沉积物和候鸟粪便的影响, 丰水期主要是土壤有 机氮,秋季枯水期主要有藻类有机氮,这些氮同位素值有显著差异(图 3,4).

鄱阳湖具有过水性的特点,主体航道水交换快,营养物质不易滞留,而其边缘的小湖泊在枯水季节水流 缓慢, 几乎没有水交换, 来自于丰水期河流的有机质和无机盐容易滞留在湖内, 而且退水后湖水浓缩, 营养 物浓度升高, 容易发生富营养化, 无机氮同位素示踪氨氮和硝酸盐氮的来源也表明鄱阳湖边缘湖泊容易蓄 积营养盐 ${ }^{[39]}$. 因此鄱阳湖的碳氮生物地球化学循环往往发生在其边缘湖泊, 有效地控制边缘湖泊的氮负荷 对于鄱阳湖的生态环境尤为重要.

\section{3 结论}

$\delta^{13} \mathrm{C} 、 \delta^{15} \mathrm{~N}$ 结合 $\mathrm{C} / \mathrm{N}$ 示踪湖泊有机质的来源, 表明不同水位不同月份悬浮有机质的来源差异较大. 5 月 水位上涨时期, 河湖连通, 大湖池和沙湖的悬浮有机质主要来源于河流运输的土壤有机质, 湖内表层沉积物 有一定贡献 $(16 \%) ; 8$ 月丰水期,河湖连通且水位最高但水交换不彻底, 悬浮有机质主要来源于滞留的土壤 有机质, 水生浮叶植物有一定贡献 $(25 \%) ; 10$ 月秋季枯水期, 河湖分离近 1 个月, 悬浮有机质主要来源于藻 类 $(77 \%)$, 表层沉积物有一定贡献; 12 月冬季枯水期悬浮有机质主要来源于表层沉积物和候鸟粪便 $(45 \%)$; 春季枯水期 3 月和 4 月悬浮有机质主要来自表层沉积和湿地植物碎屑.

\section{4 参考文献}

[ 1 ] Gu B, Chapman AD, Schelske CL. Factors controlling seasonal variations in stable isotope composition of particulate organic matter in a softwater eutrophic lake. Limnology and Oceanography, 2006, 51(6) : 2837-2848.

[ 2 ] Hein T, Baranyi C, Herndl JG et al. Allochthonous and autochthonous particulate organic matter in floodplains of the River Danube: the importance of hydrological connectivity. Freshw Biol, 2003, 48: 220-232.

[ 3 ] Eckard RS, Hernes PJ, Bergamaschi BA et al. Landscape scale controls on the vascular plant compo-nent of dissolved organic carbon across a freshwater delta. Geochim Cosmochim Acta, 2007, 71 : 5968-5984.

[ 4 ] Xie YX, Xiong ZQ, Xing GX et al. Assessment of nitrogen pollutant sources in surface waters of Taihu Lake region. Pedosphere, 2007, 17: 200-208.

[ 5 ] Xiao HY, Liu CQ. Sources of Nitrogen and sulfur in wet deposition at Guiyang, southwest China. Atmos Environ, 2002, 
36: 5121-5130.

[6] Wantzen KM, Rothhaupt K, Mortl M et al. Ecological effects of water-level fluctuations in lakes: an urgent issue. Dev Hydrobiol, 2008, 204 : 1-4.

[ 7 ] Leira M, Cantonati M. Effects of water-level fluctuations on lakes: an annotated bibliography. Hydrobiologia, 2008,613 (1) : 171-184.

[ 8 ] Wan JB, Yan WW. Evaluation methods application in and probing into eutrophication of Poyang Lake area. Journal of Jiangxi Normal University: Natural Science, 2007, 31(2) : 210-214. [万金保, 间伟伟. 鄱阳湖水质富营养化评价方 法应用及探讨. 江西师范大学学报: 自然科学版, 2007, 31(2) : 210-214.]

[ 9 ] $\mathrm{Hu} \mathrm{CH,} \mathrm{Jiang} \mathrm{JH,} \mathrm{Zhu} \mathrm{HH.} \mathrm{Analysis} \mathrm{on} \mathrm{water} \mathrm{level} \mathrm{relationships} \mathrm{between} \mathrm{Banghu} \mathrm{depression} \mathrm{and} \mathrm{Poyang} \mathrm{Lake} \mathrm{and} \mathrm{its}$ submersion and emersion of bottomland. Oceanologic et Limnologia Sinica, 1997, 28(6): 617-623. [胡春华, 姜加虎, 朱海虹. 蛙湖与鄱阳湖水位关系及滩地淹露分析. 海洋与湖沼, 1997, 28(6) : 617-623. ]

[10] Jiang JH, Huang Q. Analysis on relationship of water exchange between Banghu Lake and Poyang Lake. J Lake Sci, 1996, 8(3) : 208-214. DOI: 10.18307/1996.0303. [姜加虎, 黄群. 蚌湖与鄱阳湖水量交换关系的分析. 湖泊科学, 1996, $\mathbf{8}(3): 208-214$. ]

[11] De Lecea AM, Cooper R, Smit AJ. Identifying the drivers of the pelagic ecosystem of an oligotrophic bight (KwaZulu-Natal, South Africa) using stable isotopes $\left(\delta^{13} \mathrm{C}, \delta^{15} \mathrm{~N}\right)$ and $\mathrm{C}: \mathrm{N}$ ratio analysis. Marine and Freshwater Research, 2016, 67(11): 1750-1761.

[12] Yu J, Zhang H. Seasonal variations and sources of carbon and nitrogen isotopes in suspended particulate matter in inflow rivers of the Bohai Sea and the North Yellow Sea. Marine Sciences, 2017, 41(5): 93. [于靖, 张华. 渤海及北黄海河流 悬浮颗粒碳氮同位素时空分布及源解析. 海洋科学, 2017, 41(5): 93.]

[13] Savoye N, Aminot A, Treguer P et al. Dynamics of particulate organic matter $\delta^{15} \mathrm{~N}$ and $\delta^{13} \mathrm{C}$ during spring phytoplankton blooms in a macrotidal ecosystem (Bay of Seine, France). Marine Ecology Progress Series, 2003, 255: 27-41.

[14] Liu CQ, Lang YC, Li SL et al. Researches on biogeochemical processes and nutrient cycling in karstic ecological systems, southwest China: A review. Earth Science Frontiers, 2009, 16(6): 1-12. [刘丛强, 郎枅超, 李思亮等. 喀斯特生态系 统生物地球化学过程与物质循环研究: 重要性、现状与趋势. 地学前缘, 2009, 16(6): 1-12.]

[15] Wu Z, Cai Y, Liu X et al. Temporal and spatial variability of phytoplankton in Lake Poyang: the largest freshwater lake in China. J Great Lakes Res, 2013, 39: 476-483.

[16] Wang ML, Lai JP, Hu KT et al. Compositions of stable organic carbon and nitrogen isotopes in wetland soil of Poyang Lake and its environmental implications. China Environmental Science, 2016, 36(2) : 500-505. [王毛兰, 赖建平, 胡珂图等. 鄱阳湖湿地土壤有机碳氮同位素特征及其环境意义. 中国环境科学, 2016, 36(2): 500-505.]

[17] Wang ML, Zhang DL, Lai JP et al. Distribution and sources of stable organic carbon and nitrogen isotopes in suspended particulate organic matter of Poyang Lake. China Environmental Science, 2014, 34(9) : 2342-2350. [王毛兰, 张丁苓, 赖建平等. 鄱阳湖水体悬浮有机质碳氮同位素分布特征及来源探讨. 中国环境科学, 2014, 34(9): 2342-2350.]

[18] Zhao Z, Wang Y, Zhang L et al. Bioaccumulation and tissue distribution of organochlorine pesticides (OCPs) in freshwater fishes: A case study performed in Poyang Lake, China's largest lake. Environmental Science and Pollution Research, 2014, $21(14): 8740-8749$.

[19] Dai GF, Zhang M, Feng ML et al. Analysis of cyanobacteria bloom in Nanjishan Natural Reserve in Poyang Lake. Ecological Science, 2015, 34(4): 26-30. [戴国飞, 张萌, 冯明雷等. 鄱阳湖南矶湿地自然保护区蓝藻水华状况与成因分 析. 生态科学, 2015, 34(4): 26-30.]

[20] Liang Y, Xiao HY, Liu XZ et al. Carbon and nitrogen stable isotopes tracing nitrogen pollution in major flooding season in Lake Bang, Lake Poyang Basin. J Lake Sci, 2018, 30(4) : 957-966. DOI: 10.18307/2018.0409. [梁越, 肖化云, 刘小 真等. 碳氮稳定同位素示踪鄱阳湖流域蚌湖丰水期的氮污染. 湖泊科学, 2018, 30(4)：957-966.]

[21] Hu CH, Huang D, Zhou WB et al. Study on trophic status and influencing factors of typical lake fringe area in wet season—A case study of Banghu Lake. Journal of Hydroecology, 2013, 34(3): 32-38. [胡春华, 黄丹, 周文斌等. 典型湖 泊边缘区丰水期营养状态及其影响因子研究——以蚌湖为例. 水生态学杂志, 2013, 34(3): 32-38.]

[22] Wu YH, Ji WT eds. Study on Jiangxi Poyang Lake National Nature Reserve. Beijing: China Forestry Publishers, 2002. [ 吴英豪, 纪伟涛. 江西省鄱阳湖国家级自然保护区研究. 北京: 中国林业出版社, 2002.]

[23] Hu ZB. The habitat characteristics of white cranes to live through the winter in Poyang Lake and the reaction for water level 
changing in the lake. Jiangxi Sciences, 2012, 30(1): 30-36. [胡振鹏. 白鹤在鄱阳湖越冬生境特性及其对湖水位变 化的响应. 江西科学, 2012, 30(1): 30-36.]

[24] Phillips DL, Gregg JW. Source partitioning using stable isotopes: coping with too many sources. Oecologia, 2003,136 (2) : 261-269.

[25] Hu QQ, Liang Y, Ding XH et al. Study on trophic state of the edge lake of Poyang Lake-The cases of Dahuchi Lake and Lake Shahu. Joural of Anhui Agriculture Science, 2018, 9: 79-83. [胡倩倩, 梁越, 丁新航等. 鄱阳湖边缘湖区水体营 养状态分析——大湖池和沙湖为例. 安徽农业科学, 2018, 9: 79-83.]

[26] Cristian R, Teodoru PA, Giorgio YT. Depositional fluxes and sources of particulate carbon and nitrogen in natural lakes and a young boreal reservoir in Northern Que'bec. Biogeochemistry, 2013, 113: 323-339.

[27] Torres IC, Inglett PW, Brenner M et al. Stable isotope $\left(\delta^{13} \mathrm{C}\right.$ and $\left.\delta^{15} \mathrm{~N}\right)$ values of sediment organic matter in subtropical lakes of different trophic status. J Paleolimnol, 2012, 47: 693-706.

[28] Kanduc T. Characterisation of suspended matter in river systems: river Sava in Slovenia case study. Geologija, $2011, \mathbf{5 4}$ : $55-66$.

[29] Xiao HY, Liu CQ. Identifying organic matter provenance in sediments using isotopic ratios in an urban river. Geochemical Journal, 2010, 44: 181-187.

[30] Sigleo AC, Macko SA. Carbon and nitrogen isotopes in suspended particles and colloids, Chesapeake and San Francisco estuaries, USA. Estuarine, Coastal and Shelf Science, 2002, 54: 701-711.

[31] Dean WE. The carbon cycle and biogeochemical dynamics in lake sediments. Journal of Paleolimnology, 1999, 21(4): 375-393.

[32] Editorial Board of Study on Poyang Lake ed. Study on Poyang Lake. Shanghai: Shanghai Scientific \& Technical Publishers, 1988. [《鄱阳湖研究》编委会. 鄱阳湖研究. 上海: 上海科技出版社, 1988.]

[33] Liang Y, Liu X, Xiao H et al. Impact of high water level fluctuations on stable isotopic signature of POM and source identification in a floodplain lake-Bang Lake (Poyang Lake). Environmental Earth Sciences, 2016, 75(3) : 255.

[34] Zhang JM, Zhang M, Kuang WM et al. Characteristics of stable carbon and nitrogen isotope signatures of aquatic plants to algal blooms in Poyang Lake. Research of Environmental Sciences, 2016, 29(5) : 708-715. [张金美, 张萌, 匡武名等. 水华条件下鄱阳湖区植物叶片碳氮同位素特性. 环境科学研究, 2016, 29(5):708-715.]

[35] Gu B. Variations and controls of nitrogen stable isotopes in particulate organic matter of lakes. Oecologia, 2009, 160: 421-431.

[36] Gu B, Schelske CL, Waters MN. Patterns and controls of seasonal variability of carbon stable isotopes of particulate organic matter in lakes. Oecologia, 2011, 165: 1083-1094.

[37] Hu CH, Zhou WB, Xiao HY et al. Eutrophication state and normal distribution features of Poyang Lake. Yangtze River, 2010，41(19)：64-68. [胡春华, 周文斌, 肖化云等. 鄱阳湖富营养化现状及其正态分布特征分析. 人民长江, 2010, 41(19): 64-68.]

[38 ] Liang Y, Xiao H, Liu X et al. Spatial and temporal water quality characteristics of Poyang Lake Migratory Bird Sanctuary in China. Chinese of Journal Geochemistry, 2015, 34(1) : 34-48.

[39] Liang Y, Xiao H, Liu X et al. Variation in sources of inorganic nitrogen under different hydrological conditions in a floodplain lake: A case study of Bang Lake (Poyang Lake, Jiangxi Province, China). Inland Waters, 2018, 8(2) :176-185. 